\title{
Learning Needs and Quality Care Among Family Caregivers and Elderly Patients of Guadalupe, Cebu City, Central Philippines
}

\author{
Ivan Cliff Chan Alvarez, MSN, RN \\ Clinical Research Nurse, Cebu City Prospective Cohort Study (CPC) \\ Philippines-AFRIMS Virology Research Unit (PAVRU), Central Philippines
}

Marylou B. Ong, DScN, DM, RN

Professor III, College of Nursing, Cebu Normal University (CNU),

Central Philippines

Ferdinand T. Abocejo, $\mathrm{MPP}, \mathrm{PhD}(\mathrm{c})$

University Research Specialist, Center for Research and Development,

Cebu Normal University (CNU), Central Philippines

doi: 10.19044/esj.2017.v13n24p356 URL:http://dx.doi.org/10.19044/esj.2017.v13n24p356

\begin{abstract}
This study assessed the learning needs of the family caregivers based on knowledge, skills, attitude and values (KSAV), their quality of care services and the elderly patients' assessment on the quality of the provided care. The study utilised a descriptive-normative method employing survey research design utilizing a randomized cluster sampling technique. Primary data were collected using a standardised modified interview guide. Face-toface interviews were carried out to family caregivers and elderly patients in Guadalupe Village, Cebu City, Central Philippines. Findings revealed that caregiving jobs are mostly handled by women. Likewise, there were more female than male elderly patients, almost three-fourths of them attained high school or lower level education. Family caregivers' possessed very good attitude and values. They were also good in terms of knowledge and skills toward the care of elderly patients. Similarly, elderly patients view their caregivers to be very good in attitude and values and good in terms of knowledge and skills. In conclusion, the learning needs among family care givers dealt more on understanding the nature, medical conditions, medication administration, caregiving techniques, diet and nutrition, ambulation techniques and strategies, financial supports from peers and total care management of the elderly patients. The provision of these learning needs anchored on the knowledge, skills, attitude and values ensures the caregivers from experiencing depressions, desperations, and self-isolation.
\end{abstract}


Keywords: Family caregiver, elderly patients, quality of care, learning needs, knowledge, skills, values, attitude, general systems theory

\section{Introduction}

Family caregivers assume a major responsibility in our health care system by giving a notable contribution of the care for both chronically ill and aging elderly family member. Family caregivers give the majority of long-term care to the elderly patient (Levine et al., 2004). Their works encompass unpaid cares given to an older family member, spouse, friend, or neighbour in family relationships who is functionally dependent or chronically ill (Schumacher, Beck, and Marren, 2006). The scope of caregiving involves support with activities of daily living (ADL), care of illness-related symptoms and management of care (Walker, Pratt, and Eddy, 1995). ADL activities cover self-care practices such as taking a shower, feeding and changing clothes, exercise, bed to chair transport, using the toilet, food preparation, buying groceries, making phone calls and financial budgeting.

The family caregivers' capacity to give and deliver quality health care in managing elderly related diseases and functional dependence is an essential health care resource. Family caregivers must develop a strong foundation of knowledge, extraordinary skills and right values and attitude to effectively fulfil a patient's need. Given (2001) reported that many family caregivers lack appropriate skills and basic knowledge to meet and sustain caring for patients with severe physical dependence brought by illness, in so doing, they are not confident and feel disinclined.

In the present health care system, the main focus and centre of assessment are patients as direct recipients of care and attention (Gargar Cutamora and Abocejo, 2017). However, there are only few evidences that an assessment to patient's family caregivers was carried out. After hospitalization of elderly patients, many family members would presume that family caregivers will continue the health care continuum.

Assessing and evaluating family caregivers' competence to give quality care and recognizing family caregivers who require guidance and training are crucial in developing patient outcomes. Family caregivers may face crucial challenges while taking care of an elderly patient, especially in the aspects of knowledge, skills, attitudes and values. They need to adjust because of the broad array of cognitive, behavioural, motor, and functional impairments brought and associated with aging that changes over time. Caregivers need knowledge, skills and decisions to carry out the daily routines of care for older adults. Scherbring (2002) revealed that caregivers 
who express readiness and understanding about elderly family member caregiving delivered care with a smaller amount of burden.

In this study, we endeavoured to explore quality care service provided to the elderly patients who received direct care supervision from their family caregivers. We hope to reinforce the dynamic field of elderly nursing health care, that it be holistically directed towards the promotion of wellness and total quality care for the elderly with compassion.

\section{Theoretical-Conceptual Framework}

This study anchored its theoretical framework on General System's Theory of Von Bertalanffy (as cited in Glennister, 2011) which served as the model for viewing the interaction between the person and his environment. The Theory's attributes encompass interacting elements that connect and individual with his environment and the various elements interacting as a whole because of the connections of the system's parts. In effect, when part of the system breaks down, it impedes and restricts the purpose of the entire system, not just disturbing purely one area.

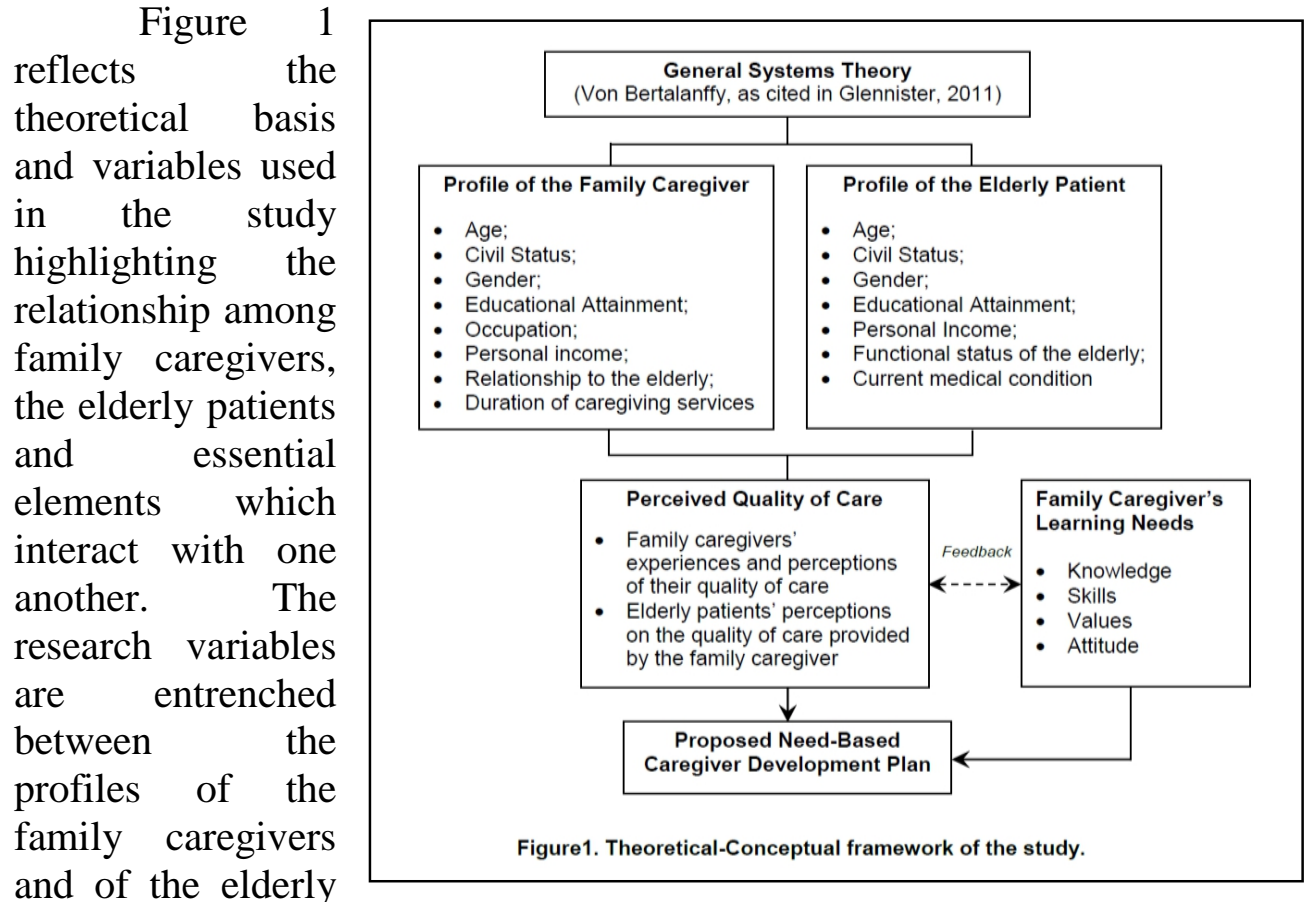

patients. These variables stem from the research environment that is inherent to the system as explained by the General Systems Theory (Von Bertalanffy, as cited in Glennister, 2011). The demographic information (such as age, civil status, gender, etc.) and relationship among the family caregivers with their elderly patients are the explanatory variables. 
The research indicators include the perceptions of quality of care by the family caregivers and the elderly patients. These perceptions from the family caregivers and elderly patients about the quality caregiving system then give feedback to the learning needs criteria used in this study which are knowledge, skills, attitude, and values. Out from this feedback, we analysed and interpreted the internal functioning of the entire caregiving system.

\section{Study objectives}

In general, we assessed the learning needs of family caregivers and their assessment of the quality of care in relation to their KSAV and the elderly patients' views on the quality of care provided by the family caregiver. Moreover, the study analysed the profile of the caregivers with respect to age, civil status, gender, educational attainment, occupation, personal income, relationship to the elderly, and duration of caregiving services. Similarly, we also examined the profile of the elderly according to age, civil status, gender, educational attainment, personal income, functional ADL and current medical condition.

Anchored on the study framework, we investigated how the family caregivers assessed their quality of care and experiences based on their KSAV in the care of the elderly and how the elderly regard the quality care provided by the family caregivers.

\section{Scope and Limitation}

This study focused only in the assessment of the quality care as viewed by the family caregivers and elderly patients. One basis of respondents' selection is a dependent elderly living together with the family caregiver within one household. This study does not offer complete resolution to the elderly care problem, but an intensive evaluation of the situation and the learning needs of the family caregivers in taking care of their elderly.

\section{Review of the Literature}

According to WHO, health education is one of the most important methods of teaching and facilitates in altering the performance and skill through mental and emotional behavioural changes. Every person is accountable for guiding and improving his own health (Gargar, Cutamora, and Abocejo, 2017). Conducting health teaching will mostly develop and benefit the person, the entire community as well as social health and development. Assessing family caregivers' competence in assuming a caregiver role in the family is a vital consideration that needs an urgent attention in any health care setting. Petronilho (2007) studied family caregivers in Portugal and his findings showed that there was a mark of 
knowledge gaps in the concepts of muscles and bones, skin, and airway processes, as well as managing pressure sores and foot injuries.

The concepts of caregiver knowledge were further studied by Graham, Ivey, and Nuehauser (2009) and they concluded and referenced that many family caregivers reported the need and importance of study materials such as the internet as a source of knowledge in the care of elderly patients. Schumacher et al. (2000) defined skill as the ability to undertake the nine core caregiving processes effectively and smoothly. They noted that prevention of complications is the best outcomes of care and this indicates that caregiver skill is effective. In addition, they claimed that skill is honed through experience and practice. Their study identified and categorised nine indicators about caregiving skill and processes: creating valuable adjustments, administering primary care, supervising, analysing, decisionmaking, initiating actions, maximizing resources and support, collaborating with the dependent person, and mobilizing the health care system.

Azoulay et al. (2000) surveyed 544 family members and 2754 ICU staff participated and recruited from the 78 ICU in France to evaluate the attitude of families and health staff about family involvement in caregiving their functional dependent relatives. The findings of their study showed that among the staff, 88.2 percent attested that involvement in patient care be delegated to the families. However, only 33.4 percent of the family members stated that they wanted to collaborate in patient care.

$\mathrm{Ng}$ (2008) investigated the family caregivers' attitude and values while they were taking care of their aged and dependent relatives for identifying the characteristics and the different care giving experience. In his extensive survey, a large part of the caregiver was married and belonged to the middle-aged bracket. Sixty (60) percent of the total population belonged to the working group in the society and about 40 percent of them were under retirement.

Communication is very essential to the relationship between the caregiver and the care recipient as they spent a considerable amount of time communicating with their patients during caregiving. Kruzich et al. (2003) implemented a study to recognise the perceptions of the family caregivers about the barriers of involvement in caring their care recipients. The insights and perceptions of family caregivers were checking to find the amount and type of participation they provided to the children as well as determining the different barriers and support to caregiver's participation. The results and conclusions of the study revealed a lack of communication between the staff member and the family caregivers. The study showed that the pessimistic attitude of the health care staff caused the barrier in care participation.

To understand more of the experiences and gaps of caregiving, Mochari-Greenberger (2012) studied the effect of caregiver burden and 
capability as indicator of health care improvement. This study is focusing on examining the resources, burden and competency of the caregivers in relation to the caregiving process of older patients. Data collection was performed through personal interviews from 240 sampled caregivers selected randomly. The findings of the study revealed that personal and social resources were present among the caregivers and the amount of caregiver burden is highly related to the nature of their job.

Shinde and Anjum (2009) evaluated the effects of the demonstration among caregivers concerning hemiplegia patients during administration of nutritional feedings. The outcome of the study showed that the majority of the caregivers belong to 28-37 years old, 53-63 percent was females, 40-60 percent was unemployed and 70-80 percent was married.

Wittenberg-Lyles et al. (2011) indicating that the majority of the family caregivers are deficient of the basic knowledge and skills in providing quality care for a person with functional dependence, such that they lack confidence and felt unprepared to provide care. Data revealed that caregivers were given minimum guidance from health care providers, and that they have no background in caring, and they are unfamiliar with the roles and functions, as well as inability to access and use health care resources.

Evans et al. (2010) observed children receiving enteral feedings in the areas of home safety. In their study, they assessed the caregiver's competence and mastery in the delivery of safe tube feedings. Out of forty respondents, 50 percent was given gastrostomy feedings and another 50 percent were on NGT feeding. A questionnaire and interview questions were given to the caregivers. The study revealed the following major issues such as hygienic practices (78 percent), inadequate hand washing techniques (25 percent), unable to perform tube flushing (50 percent), failure to check tube's placement (40 percent), the evident lack of knowledge on how to prime tube blockages (80 percent), no adequate education and trainings among caregivers (43 percent). Silver et al. (2004) recommended the need for carrying out trainings, especially in the aspect of the tube feeding task of caregiving.

Shinde and Anjum (2014) assessed the techniques of feeding employed by caregivers before and after the demonstration and determined the relationship between demographic data and feeding skills. Sixty (60) respondents with study treatment were recruited to participate in the study in order to assess the efficacy in both oral and NGT feeding. Half of the respondents were chosen for oral feeding determinants and other 30 were preferred for the NGT tube feeding indicator. The findings of the study showed that there is a considerable enhancement of skill among caregivers after the demonstration. In addition, the data revealed that there is no 
considerable connection between the caregivers' skill and their age, sex, education, occupation and marital status (Shinde and Anjum, 2014).

Scheinmann, et al. (2010) investigated the effects of a multimedia video was given to the respondents to both experimental and control groups for home showing. Both respondent mothers were on the same age, educational attainment and number of pregnancies. The study results showed that an increase in knowledge was manifested by the mothers after a sixmonth follow up.

\section{Research Methodology \\ Research Design}

This study employed the descriptive-normative survey research design which dealt with the collection of information from the respondents through seeking out their responses to questions stipulated in the standardised questionnaire.

\section{Research Locale}

This study was implemented to family caregivers and elderly patients among low income groups or marginalised families of Guadalupe Village in Cebu City, Central Philippines. Among the Cebu City communities, Guadalupe hosts the largest population counts of 61,238 residents (Philippine Statistics Authority [PSA], 2015). The area selection was based to the presence of large family caregivers and elderly patients in the study area.

\section{Research Respondents}

The research respondents were family Caregivers for the elderly among low income groups or marginalised families in the study area. Based on the data provided by the Office of the Senior Citizens Affairs (OSCA, 2014), a total of 4,112 registered senior citizens (60 years old above) were residing in the study area. A total of 140 elderly senior citizens were identified as physically dependent, they were bedridden, wheel-chaired and elderly patients who had mild to severe stroke cases. Upon consideration of the inclusion criteria, only 65 qualified to be the actual respondents which were based on the following inclusion criteria to be included in the sample. They Actual respondents (a) belong to a marginalised family, (b) be a family member of the elderly they are taking care of, (c) be living with the elderly in the same household, (d) at least taking care of one elderly dependent and (e) should not be a health care professional. A cluster random sampling technique was employed in getting the 65 actual respondents. 


\section{Research Instrument}

We adapted and modified a research questionnaire from a study of Ang (2008). The first part of the questionnaire was an inquiry on the demographic data of the family caregiver which includes the age, civil status, gender, and educational attainment, occupation, personal income, and relationship with the elderly. Also included was the profile of the elderly in terms of age, gender, civil status, educational attainment, personal income, functional status of the elderly (KATZ ADL), and their current medical condition. The second part consisted of statements related to the family caregiver's perception on their quality of care in terms of knowledge, skills, attitude, and values in rendering care to the elderly. The family caregivers were asked to read and rate each situation. The third part was an essay focusing on identifying the experiences of the family caregivers in taking care of their elderly dependents. The last part was answered by the elderly dependent. The elderly patient were being assisted in their answering of the questionnaire.

\section{Data Gathering Procedure}

We conducted an active home surveillance among the identified dependent-elderly patient's family caregivers in the study area. A letter seeking permission to implement the research in study area was secured from the Village Chairman. Upon approval, we implemented the study to identified randomly chosen respondents through active home visiting and recruitment processes.

The target respondents were screened to determine if they qualified based on inclusion criteria. For those who qualified, they received a study briefing describing the study to include, but not limited to: study objectives, risks and potential benefits of participation, and enrolment requirements. If the respondents remain interested in participating, they would sign an informed consent form. Question and answer sessions occurred throughout the process. Every prospective respondent had an opportunity to discuss expectations and details of the study. All questions were answered to the satisfaction of the respondents prior to signing the informed consent form. Once the form was signed, the respondents were recruited to participate in the study.

\section{Treatment and Analysis of Data}

The gathered data were treated to generate summary statistics needed to answer the stated study objectives which included frequency count, percentages, arithmetic mean, weighted mean (WM), mode and standard deviation (SD) To determine the functional status of the elderly, the rubric for Katz Index of independence in ADL was be followed. For the qualitative 
textual and narrative data, content and thematic analysis were utilised. All statistical calculations were done using MS Excel for Windows and Minitab 16 software free trial version.

\section{Discussion of Results}

Profile of the Family Caregiver

The majority of caregiver respondents (Figure 2) were females accounting for 89 percent while their male counterpart comprised only 11 percent. This reflects that the provision of caregiving in the study area is largely handled by women. In fact, caregiving is a woman's task commonly done by the

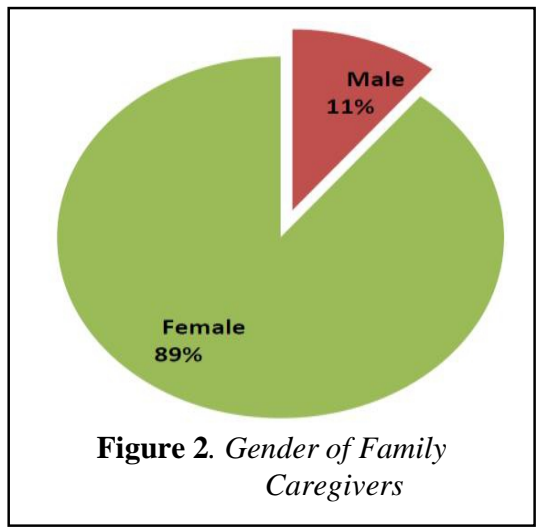
daughter of the care giving recipients (Robles-Silva, 2000). As indicated by some female respondents, they feel obligated to offer care to their elderly

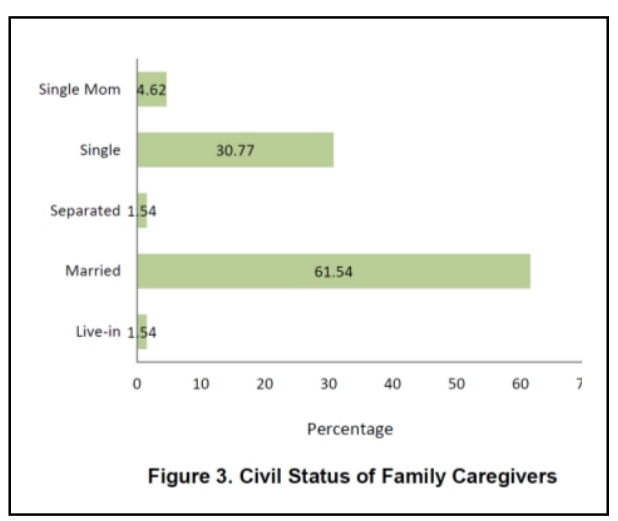

family members. This also because male family members are usually outside the home working to earn for a living. Other women claimed that they are more compassionate and gentle when it comes to rendering care to elderly patients. They also noted that men do not usually assume the caregiver role to conserve and protect their "macho" image. Women tend to do most things by their own selves, and would rather not delegate nor ask help; however, men usually assign tasks to someone who is more fitted to do the job (Bauer and Sousa-Poza, 2015).

As to civil status (Figure 3), almost two-thirds were married at about 62 percent of the total respondents with about 31 percent single and nearly five percent single mom.

These findings confirm the study of Suitor and Pillemer (1996) which stressed that caregiving is carried out by the elderly patients' married children since they are matured already in terms of responsibility and social support, while the elderly patients' single children are

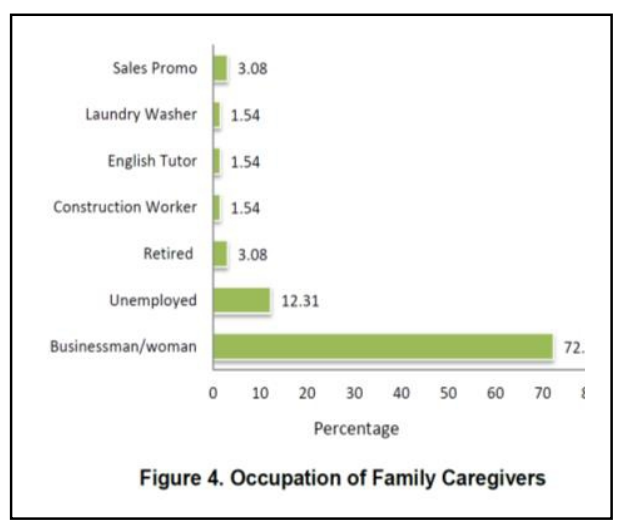


likely to move out from their parents' houses to look for a job or source of income.

Interestingly, most respondents were businesswomen accounting 72 percent of the entire sample (Figure 4). They affirmed that doing small business within their family is more practical so that they can still balance their caregiving responsibilities towards the elderly rather than being employed distant from home. Caregivers sometimes have to sacrifice their jobs by arriving late or leaving the office early, engage in part time work instead full time employment, and sometimes may decline promotions. Practically, keeping a job while caring for a family member is a very challenging difficult task (Clark and Weber, 1997).

Table 1. Relationship Between Educational Attainment and KSAV

\begin{tabular}{||c|c|c|c||}
\hline Variable & $\begin{array}{c}\text { Degree of } \\
\text { Freedom }\end{array}$ & $\mathbf{X}^{\mathbf{2}}$-Value & P-Value \\
\hline Knowledge & 8 & $19.946^{*}$ & 0.015 \\
\hline Skills & 8 & $10.812^{\text {ns }}$ & 0.213 \\
\hline Attitude & 8 & $13.490^{\text {ns }}$ & 0.096 \\
\hline Values & 8 & $13.465^{\text {ns }}$ & 0.097 \\
\hline \multicolumn{4}{|c|}{ ns - not significantly related } \\
* - significantly related at $\alpha=0.05$ \\
\hline
\end{tabular}

On the other hand, the findings revealed that 12 percent of the total respondents were unemployed and worked as full time caregivers to their elderly family members.

Furthermore, nearly all respondents fall within income group of about $\mathrm{PhP} 2,000$ per month earning. Only one respondent had a monthly income above PhP4,000 (Figure 5) affirming that the majority belong of caregivers belong to poor or marginalised families where financial expenses for their elderly members pose a major problem. Evidently, caregivers' monthly income is far below the monthly income per capita of Php10,534 poverty thresholds based on the Philippine Statistics Authority (2015) classification. As expected, about three-fourth or 75 percent of the respondents derived their income from businesses. About 11 percent obtained income from employment and remittances with a small 3 percent relied on their pensions.

By educational attainment (Figure 6), close to 62 percent of the respondents completed high school (HS) level education, 12 percent were HS graduates while 18 percent reached college level. Data revealed that, the higher the educational attainment is significantly associated with knowledge. High school and college level caregivers tend to have

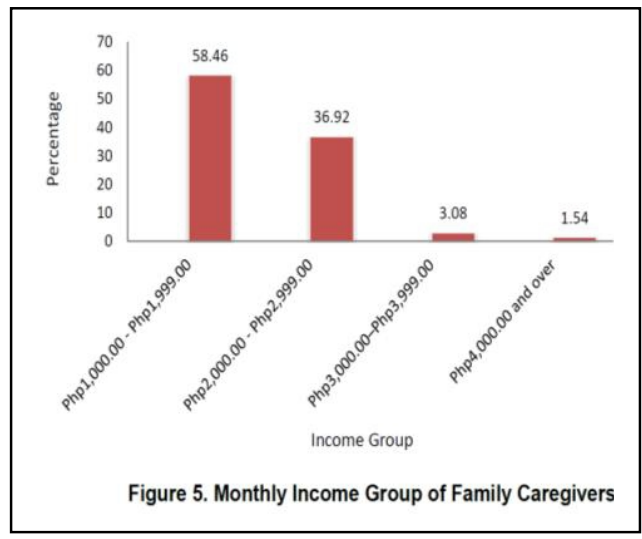


good and very good knowledge about providing caregiving services towards their elderly (Table 1). In essence, education provides the basic training to the caregivers on how to take care of their elderly with regards to knowledge and skills. The findings further demonstrate a significant association knowledge and skills of the caregivers (Table 1). Caregivers who have formal trainings on caregiving appear to be more confident and effective in rendering care towards their elderly members whereas those with no background tend to be less effective and anxious.

Slightly over two-thirds (66 percent) of the respondents were sons and daughters of the elderly. About one-fourth or 24 percent were are grandsons and granddaughters, three percent were spouses while the rest (6 percent) were nieces or nephews of the elderly patients. A little over onethird (38 percent) among the respondents were taking care of their elderly between one and two 2 years. Meanwhile, 17 percent have rendered long caregiving services of more than five years.

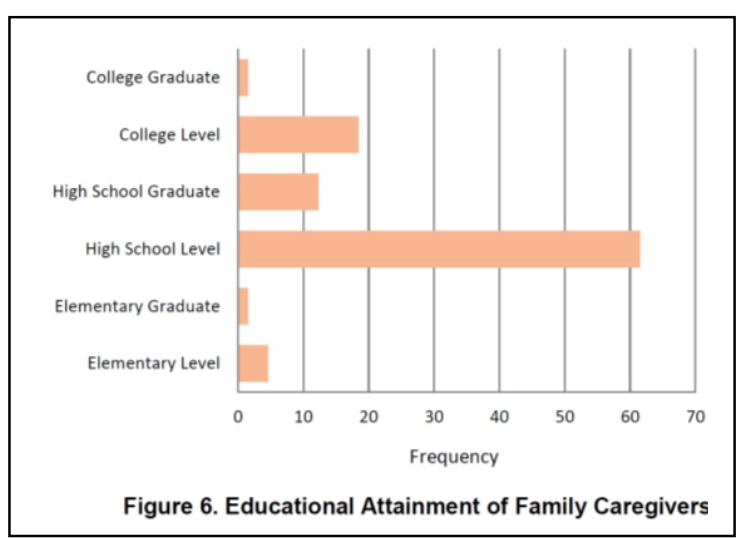

The mean age of the respondents was 31.51 years, manifesting a relatively young group of people taking care of their elderly. At the onset, the same standard deviation (SD) of 10.26 years reflect that while family caregivers where relatively in their $30 \mathrm{~s}$, some were at an advanced age while others were still young. Apparently, a large proportion

of the respondents are within middle-adult stage where depression and anxiety symptoms are very common (Christensen et al., 1999). It can be deduced that the negative impact on caregiver relationship and social networks at this age group is high risk due to their reduced ability to participate in activities outside their caring role which in turn can lead to social isolation.

\section{Profile of the Elderly Patient}

Two thirds (66 percent) of elderly patient respondents were females while their male counterpart were fewer by about half (34 percent) as presented in Figure 7. This suggests that life expectancy among females is longer than males (Epstein, 2007). Diseases connected to smoking and alcohol

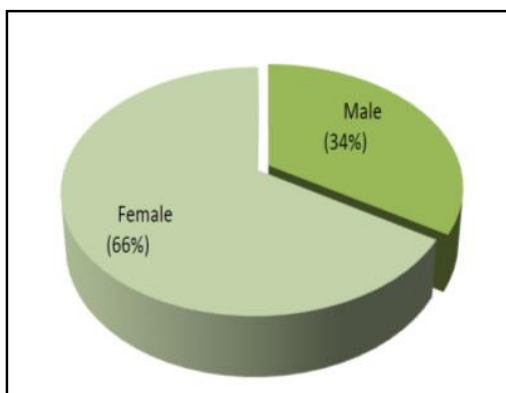

Figure 7. Gender of the Elderly 
abuse kill more males than females in this older adult age group and heart problems are the major reason for the gap of gender between the elderly (Cockerham, 2012). Men experience a higher increased threat in acquiring a heart illness starting in their 40s; in contrast, the women's danger of acquiring heart disease is low and will remain low until they reach menopause.

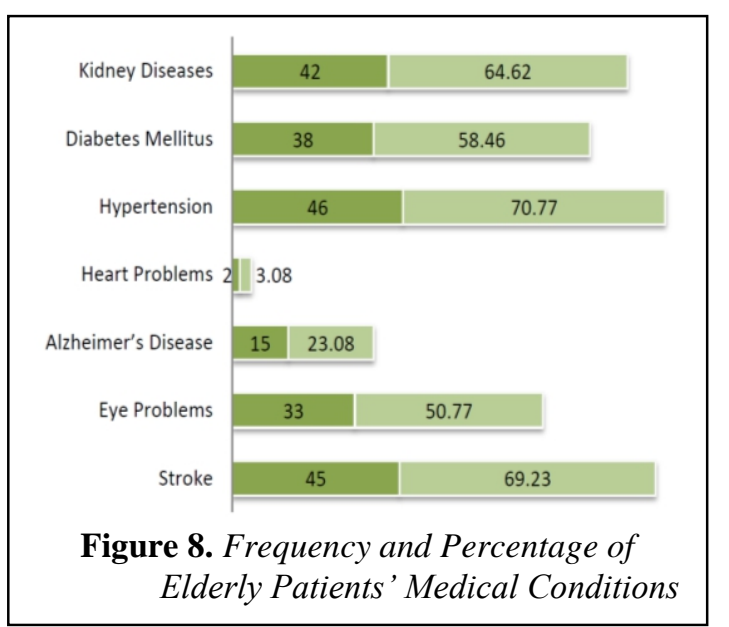

By civil status, the majority were widows/widowers at 72 percent while the remaining 28 percent were married. Visibly, elderly patients mostly have spouses who died ahead of them. Furthermore, the elderly respondents had a mean income of about $\mathrm{PhP} 1,561$ per month with only six percent having income above $\mathrm{PhP} 2,500$ per month. The bulk of elderly patients belonged to low income level groups, falling below the poverty threshold. Most of the elderly patients (94 percent) were beneficiaries of the government's retirement plan. Other sources of income include remittances and allowances given by their families and relatives at 6 percent.

By educational attainment, almost all elderly patients (97 Percent) were only able to study elementary level, only 3 percent among them were able to complete elementary studies. As one elderly respondent affirmed, poverty prevented them to continue their studies of completing elementary or proceeding to high school.

About 69 percent were diagnosed with stroke, mild stroke, and hemiplegia and muscle weakness (Figure 8). A little over half, 51 percent, were suffering from eye problems like glaucoma, cataract and decreasing eye sight. Close to one fourth (23 percent) had Alzheimer's disease and dementia, 71 percent had been diagnosed with hypertension and two 3 percent had heart problems. Kidney diseases such as kidney

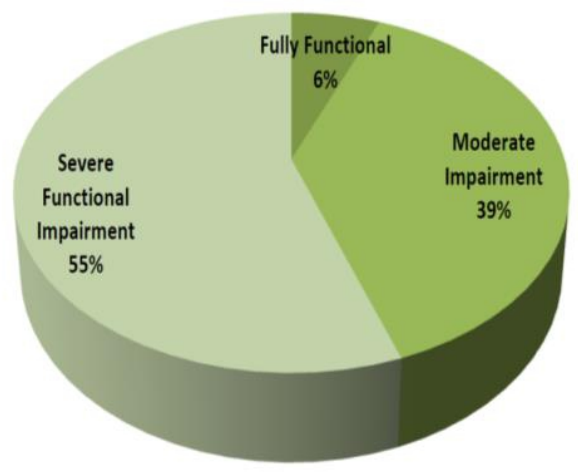

Figure 9. Katz Index of Activitiesof Daily Living (ALD) 
stones, urinary problems and nephritis were experienced by nearly threefourths (65 percent) of the total respondents.

Chronic conditions arise once the person reaches the older age level. Elderly with worsening health status are limited in their ADL by their condition affirming the fact that the elderly patients need extra care, they are more dependent who need more difficult and costly to manage than the health disabilities experienced by younger age groups (Chappell and Cooke, 2010). For the elderly with persistent ailments, there is a higher rate of hospital admissions (Epstein, Jha and Orav, 2011). Evidently, budget for hospital care and related services aggravated due to higher costs associated with chronic illnesses. The mean age of the research respondents was 82 years, with the standard deviation of 3.5 years. These reflect that Filipino elderly are indeed not placed in the home for the aged, instead they are taken cared of by their family members at home.

Most of the elderly respondents (55 percent) had severe functional impairment in performing activities of daily living (Figure 9). These elderly patients are bedridden, entirely dependent and need constant caregiver assistance. The other 38 percent were moderately impaired and can still carry out some basic activities of the ADL. Only six percent can perform activities of daily living (ADL) with no support from their caregivers. Functional decline among the elderly in terms of performing activities of daily living (ADLs) increases the potential for illness and injury.

\section{Family Caregivers' Perception in Terms of Knowledge, Skills, Attitude and Values}

Table 2 shows the family caregivers' perception of their quality of care based on the KSAV criteria. The result reflects that the family caregivers view themselves as having good knowledge and skills in performing caregiving tasks towards their elderly dependents. In terms of attitudes and values, family care givers affirmed to be very good, possessed

Table 2. Family Caregivers Perceptions in terms

\begin{tabular}{|c|c|c|c|}
\hline \multicolumn{4}{|c|}{ of $K S A V$} \\
\hline Variable & $\begin{array}{c}\text { Weighted } \\
\text { Mean }\end{array}$ & SD & Description \\
\hline Knowledge & 2.65 & 1.09 & Good \\
\hline Skills & 3.06 & 1.04 & Good \\
\hline Attitude & 3.69 & 0.88 & Very Good \\
\hline Values & 3.66 & 0.92 & Very Good \\
\hline $\begin{array}{r}\text { Ranges for the } \\
1.00- \\
1.81- \\
2.61- \\
3.41- \\
4.21-\end{array}$ & $\begin{array}{l}\text { ghted mean } \\
0 \\
0\end{array}$ & $\begin{array}{l}\text { Descriptio } \\
\text { Not Obser } \\
\text { Poor } \\
\text { Good } \\
\text { Very Good } \\
\text { Outstandin }\end{array}$ & \\
\hline
\end{tabular}

positive and caring attitudes towards their elderly patients.

In this study, although the research respondents did not receive adequate amount of information about caregiving, they still appear to have good knowledge and skills in caring of their elderly patients. They affirmed to have sufficient grasp about the nature of their 
elderly's medical condition, able to trace the cause and effects of their elderly's disease pattern, identify behavioural response used by the elderly, identify actual and potential problems, and to have enough knowledge about the medications of the elderly. In spite having no formal training in caregiving, their knowledge was sufficient enough to render adequate care to the elderly. This may attributed to their previous experiences with caregiving. With their previous experiences and the duration of their caregiving services, they have improved their knowledge even without undergoing any proper training. These findings confirms the study of Schank (1995) which reported that learning by directly performing the job makes the person do their job better. If someone performs a task often enough, that person will become more familiarise and will get better at it. When people start to put more effort concerning what they are performing, they may eventually discover how to make their tasks better than others (Quina, Almazan, and Tagarino, 2014).

The respondents acknowledged that care giving experiences helped them to be more effective in dealing with difficult situations, especially in carrying out some medical procedures that requires their caregiving skills. As noted, the longer their experiences as caregivers, the more effective they become in handling caregiving situations. Notably, the best way to educate any person is to allow that person do a job where the needed skills can be learned from.

As noted, many research respondents did not received adequate amount of information about caregiving, yet many possess positive attitudes toward caregiving. They claimed that notwithstanding that their tasks are very tiring and stressful, they maintained respect and courtesy towards their elderly dependents. They emphasised wearing when interacting with their elderly, ever supportive and gentle in dealing with their patients. True enough, frustrating situations happen along the way, yet they were met with patience and understanding while putting the needs of the elderly as their first priority.

Tang, Ungvari and Chan (2002) recounted that the majority of caregivers had a positive attitude toward caregiving. They reported that 65 percent of the respondents gave correct responses such as caregiving are a family obligation which promotes bonding within the family and helps the elderly to cope with

Table 3. Elderly Patients' Perceptions in terms of

\begin{tabular}{|c|c|c|c|}
\hline \multicolumn{4}{|c|}{$K S A V$} \\
\hline Variable & $\begin{array}{l}\text { Weighted } \\
\text { Mean }\end{array}$ & SD & Description \\
\hline Knowledge & 2.67 & 0.95 & Good \\
\hline Skills & 2.97 & 0.96 & Good \\
\hline Attitude & 3.55 & 0.86 & Very Good \\
\hline Values & 3.55 & 0.93 & Very Good \\
\hline $\begin{array}{r}\text { Ranges for the } \\
1.00- \\
1.81- \\
2.61- \\
3.41- \\
4.21-\end{array}$ & $\begin{array}{l}\text { ghted mean } \\
0 \\
0 \\
0\end{array}$ & $\begin{array}{l}\text { Descriptic } \\
\text { Jot Obser } \\
\text { oor } \\
\text { ood } \\
\text { ery Good } \\
\text { utstandin }\end{array}$ & \\
\hline
\end{tabular}


the disability. On the contrary, Chavan et al. (2006) noted that the caregivers had many misconceptions as well as negative attitudes towards caregiving. In his study, 40 percent of the respondents believed that caregiving is a nonrewarding job and is viewed as a day to day punishment to the caregivers.

In this study, we found that a higher percentage of the respondents observed the right values in rendering care to the elderly. Our respondents also claimed that cultural norms greatly drive them to perform their duties and responsibilities as caregivers. They added that Filipinos are naturally born family-oriented whose motivations to provide are identified through cultural traditions. Our respondents also viewed caregiving as a source of fulfilment. Rather than being seen as an additional responsibility. Indeed caregiving is viewed to be source of personal and emotional fulfilment by the people who performs it, which comes after helping out family members, satisfying cultural standards while keeping the family bond closer together.

\section{Elderly Patients' Perception in Terms of Knowledge, Skills, Attitude and Values (KSAV)}

As shown in Table 3, the weighted means for knowledge and skills perception were 2.67 and 2.97; respectively, indicating that elderly respondents had good perception of the family caregiver's knowledge about caregiving. Attitude and values registered the same weighted at 3.55 suggesting a very good perception among elderly patients' of the family caregivers' attitude towards them. Some of the elderly respondents claimed that they feel secure and confident that their caregivers are knowledgeable enough in taking care of them. They added that their caregivers always ask suggestions and questions about caregiving to health authorities and they are open for any training for improvement.

The elderly respondents also reported satisfaction with the way their caregivers handle them especially in carrying out caregiving procedures. Even without any formal training, the experience and the duration of their caregiving service makes elderly caregivers competent enough to handle routine caregiving procedures. Elderly respondents also affirmed that their caregivers are gentle and patient, always encouraging them to have positive outlook in life. Even if they are already tired and exhausted, still the elderly patients feel being cared for as their immediate needs immediately are provided, they have been supported through their condition and current medical situation. Interestingly, they confessed that their caregivers show respect and value them as a person. Sometimes, when arguments arise within the family, the elderly patients still feel secure and reassured that their caregivers are taking good care of them.

On the other hand, a small portion of elderly respondents said that their caregivers often shout and argue with them, especially during times 
when caregivers are already exhausted and tired. Another elderly patient narrated that sometimes financial issues in the family leads to tension between them and their caregivers.

\section{Experiences of the Family Caregivers}

The family caregivers were interviewed to capture their experiences and challenges to validate their perceptions of their KSAV. Accounted experiences focused on family and community supports, health care professional support, how they manage stress and ways to improve their delivery of quality care. Some caregiver respondents stressed that caregiving has been associated with a range of negative experiences, including emotional crisis, physical discomfort, guilty feeling, anxiety, and feeling of social isolation, depression, hopelessness, and financial difficulties. The family caregivers experience emotional crisis during sudden occurrences of disease symptoms which make them feel anxious and unprepared to face such difficult situations. One caregiver affirmed that she often feels frustrated and depressed by doing the same routine every day and she does not feel any relief of her current situation.

Other of the family caregivers also confessed having a guilty feeling while taking care of their elderly brought by their guilt of inadequacy and incompetence to take care of the elderly. They feel anxious in committing mistakes during caregiving tasks due to lack of basic knowledge about the elderly's condition, still others experienced physical discomforts such as fatigue and exhaustion, especially when elderly patients need assistance on mobility and carrying out some activities of daily living (ADL).

Feelings of social isolation were also common among the family caregivers and they attested to feel being left behind by their friends and families. There are times that they are no longer flexible with their schedules because they have to attend first to the needs of their elderly. Moreover, many respondents said that financial problems are very common among in their families, noting that some medications prescribed for the elderly were not bought and treatment regimen cannot be done due to financial constraints. Some family caregivers also said emphasised they lack basic knowledge and skills in caregiving, especially on medication preparation, disease management, ambulation and bathing, as well as carrying out ADLs for the elderly. Nonetheless, they emphasised that they are very willing to learn more if there are available programs to support and train as family caregivers. 


\section{Conclusion and Recommendations}

In the light of the findings of the study, we concluded that family caregivers need to learn better and deeper about understanding the nature of elderly patients' medical conditions, medication administration, caregiving techniques, diet and nutrition, ambulation techniques and strategies, lack of financial and more support from peers and management. Learning these needs may ensure the caregivers' to do away with depressions, desperations and even self-isolations. Moreover, elderly caregiving is predominantly carried out and sustained by women members in the family.

From the foregoing findings and conclusion, we recommend that health education given to family caregivers for the elderly should be standardised to include all the topics needed to equip them with sufficient knowledge and skills thereby improve quality of care. Awareness campaigns for family caregivers learning needs through a wide functional method should be advocated to provide better support and motivation to caregivers in the community. Home follow-up visits by community health nurses and barangay health workers should be implemented and sustained counselling at home level. We also recommend a need-based caregiver development program for adoption by the concerned caregivers and health care provider entities.

\section{References:}

1. Ang, S. (2008). The Novice Staff Nurses Perception on their knowledge, Skills, Attitudes, and Values Utilizing Bertalanfy's General Systems Theory. Unpublished Thesis. Cebu Normal University.

2. Azoulay, E., Chevret, S., Leleu, G., Pochard, F., Barboteu, M., Adrie, C., Canoui, P., Le Gall, J.R., \& Schlemmer, B. (2000). Half the families of intensive care unit patients experience inadequate communication with physicians. Critical Care Medicine, 28(8):30443049 .

https://www.ncbi.nlm.nih.gov/pubmed/10966293.

3. Bauer, J. M., \& Sousa-Poza, A. (2015). Impacts of informal caregiving on caregiving employment, health and family. IZA Discussion Paper Series No. 8851. Journal of Population Ageing, 8(3), 113-145. DOI: 10.1007/s 12062-015-9116-0

4. Chappell, N.L., Cooke, H.A. (2010). Age related disabilities - Aging and quality of life. (Eds. Stone and Blouin). International Encyclopedia of Rehabilitation. Retrieved from http://cirrie.buffalo.edu/encyclo pedia/en/article/189/

5. Chavan, B.S., Kumar. S., Arun, P., Bala, C., Singh, T. (2006). ECT: Knowledge and attitude among patients and their relatives. Indian 
Journal of Psychiatry, 48:34-8. Retrieved from http://www.indianj psychiatry.org/text.asp?2006/48/1/34/31616

6. Christensen, H., Jorm, A. F., Mackinnon, A. J., Korten, A. E., Jacomb, P. A., Henderson, A. S., Rodgers, B. (1999). Age differences in depression and anxiety symptoms: A structural equation modelling analysis of data from a general population sample. Psychological Medicine: A Journal of Research in Psychiatry and the Allied Sciences, 29(2), 325-339. DOI:10.1017/S0033291798008150

7. Clark, J.A., and Weber, K.A. (1997). Challenges and Choices: Elderly Caregiving. Department of Human Development and Family Studies, University of Missouri Extension. Retrieved from http://extension.

missouri.edu/explorepdf/hesguide/humanrel/gh6657.pdf

8. Cockerham, W.C. (2012). The intersection of life expectancy and gender in a transitional state: the case of Russia. DOI:10.1111/j.14679566.2011.01454.x

9. Epstein, A.M., Jha, A.K., Orav, E.J. (2011). The Relationship between hospital admission rates and rehospitalizations. The New England Journal of Medicine, 365:2287-2295. DOI: 10.1056/NEJMsa1101942

10. Epstein, L. (2007). The Female/Male Differential Life Expectancy. Myers-JDC-Brookdale Institute. Smokler Center for Health Policy Research. Retrieved from http://docshare.tips/the-female-maledifferential-in-life-expectancy_58914fc6b6d87fc0388b4612.html.

11. Evans, S.L., MacDonald, A., Daly, A., Hopkins, V., \& Holden, C. (2010). Monitoring of home safety issues in children on enteral feeds with inherited metabolic disorders. Archives of Disease in Childhood. DOI: $10.1136 /$ adc.2008.148338.

12. Gargar, A.P., Cutamora, J.C., \& Abocejo, F.T. (2017). Phlebitis, infiltration and localized site infection among patients with peripheral intravenous catheters. European Scientific Journal, 13(18),148-170. DOI: 10.19044/esj.2017.v13n18p148

13. Given, B. (2001). Nurse practitioners: Issues within managed care environment. In J. McCloskey-Dochtermen \& H. Kennedy-Grace (Edss), Current Issues in Nursing, (6 ${ }^{\text {th }}$ ed), 358-366. St. Louis, MS: Mosby

14. Glennister, D. (2011). Towards a general systems theory of nursing: A literature review. University of Hull, Hull, United Kingdom. Retrieved from http://journals.isss.org/index.php/proceedings55th/article/view/17 $17 / 569$ 
15. Graham, C.L., Ivey, S.L., \& Neuhauser, L. (2009). From hospital to home: assessing the transitional care needs of vulnerable seniors. Gerontologist. 49(1):23-33. DOI: 10.1093/geront/gnp005

16. Kruzich, J.M., Jivanjee, P., Robinson, A. \& Friesen, B.J. (2003). Family caregivers' perceptions of barriers to and supports of participation in their children's out-of-home treatment. Psychiatric Services, 54:11 (1513-1518). DOI: 10.1176/appi.ps.54.11.1513

17. Levine, C., Reinhard, S., Feinberg, L.F., Albert, S., \& Hart, A. (2004). Family caregivers on the job: Moving beyond ADLs and IADLs. Generations: Journal of the American Society on Aging, 27(4), 17- 23. 2 Retrieved from https://www.researchgate.net/publication/ 288606429_ Family_ caregivers_on_the_job_Moving_beyond_ADLs_and_IADLs

18. Mochari-Greenberger, H. (2012). Caregiver burden and nonachievement of healthy lifestyle behaviors among family caregivers of cardiovascular disease patients. American Journal of Health Promotion. 27(2): 84-89. doi: 10.4278/ajhp.110606-QUAN241

19. Ng, G.T. (2008). Singapore: Characteristics of family caregivers and care recipients and their caregiving experiences. Hallym International Journal of Aging, 10, 41-62. DOI: 10.2190/HA.10.1.c

20. Office of the Senior Citizens Affairs [OSCA]. (2014). Population of Cebu City Senior Citizen. Retrieved from https://www.cebucity.gov.ph/

21. Petronilho, F.A.S. (2007). Preparation of Homecoming ( $1^{\text {st }}$ ed). Coimbra: Formasau, Education and Health, Inc.

22. Philipine Statistics Authority [PSA] (2015). Population of Region VII - Central Visayas Based on the 2015 Census of Population. Retrieved from https://psa.gov.ph/content/population-region-vii-centralvisayas-based-2015-census-population

23. Philippine Statistics Authority [PSA]. (2015). First semester per capita threshold and incidences in poverty statistics-main page. Philippine Statistics Authority (PSA). Retrieved from www.mncsb.gov.ph/po verty/

24. Quina, C. R., Almazan, J. U., \& Tagarino, J. B. (2014). Knowledge, attitudes, and practices of leptospirosis in Catbalogan City, Samar, Philippines. American Journal of Public Health, 2(3), 91-98. DOI: 10.12691/ajphr-2-3-5

25. Robles-Silva, L. (2000). The caregiver phenomenon: An invisible result of aging. Paper presented at the Mexican Society of Demography 6th National Meeting on Demographic Research. A.C. El Colegio de México, Mexico City. 
26. Schank, R. C. (1995). What we learn when we learn by doing. Technical Report No. 60. Northwestern University, Institute for Learning Sciences. Retrieved from http://cogprints.org/637/1/LearnbyDoing_Schank.html

27. Scheinmann, R., Chiasson, M.A., Hartel, D. \& Rosenberg, T.J. (2010). Evaluating a bilingual video to improve infant feeding knowledge and behavior among immigrant Latina mothers. Journal of Community Health, 35(2):464-470. DOI:10.1007/s10900-0099202-4

28. Scherbring, M. (2002). Effect of caregiver perception of preparedness on burden in an oncology population. Oncology Nurse Forum; 29(6):E70-E76. DOI: 10.1188/02.ONF.E70-E76

29. Schumacher, K., Beck, C.A., \& Marren, J.M. (2006). Family caregivers: Caring for older adults, working with their families. American Journal of Nursing, 106(8):40-49. Retrieved from https://www.ncbi. nlm.nih.gov/pubmed/16905931

30. Schumacher, K. L., Stewart, B. J., Archbold, P. G., Dodd, M. J., \& Dibble, S. L. (2000). Family caregiving skill: development of the concept. Research in Nursing \& Health, 23, 191-205. DOI: 10.1002/1098-240X(200006)23:3<191::AID-NUR3>3.0.CO;2-B

31. Shinde, M. \& Anjum, S. (2014). Effectiveness of demonstration regarding feeding of hemiplegia patient among caregivers. International Journal of Science and Research, 3(3):19-27. Retrieved from https://www.ijsr.net/archive/v3i3/MDIwMTMxMDIy.pdf

32. Shinde, M., \& Anjum, S. (2009). Effectiveness of demonstration regarding feeding of hemiplegia patient among caregivers. International Journal of Science and Research, 3(3):19-27. Retrieved from http://www.ijsr.net/archive/v3i3/MDIwMTMxMDIy.pdf

33. Silver, H.J., Wellman, N.S., Galindo-ciocon, D. and Johnson, P. (2004). Family caregivers of adults on home enteral nutrition have multiple unmet task-related training needs and low overall preparedness for caregiving. Journal of the American Dietetic Association, 104(1):43-50. DOI: 10.1016/j.jada.2003.10.010

34. Suitor, J.J. \& Pillemer, K. (1996). Sources of Support and Interpersonal Stress in the Networks of Married Caregiving Daughters Findings from a 2-year Longitudinal Study. The Journals of Gerontology Series B Psychological Sciences and Social Sciences, 51(6):297-306. DOI: 10.1093/geronb/51B.6.S297

35. Tang, W.K., Ungvari, G.S., Chan, G.W. (2002). Patients' and their relatives' knowledge of, experience with, attitude toward, and satisfaction with electroconvulsive therapy in Hong Kong, China. 
Journal of Electroconvulsive Therapy, 18(4):207-12. Retrieved from https://www.ncbi.nlm.nih.gov/pubmed/12468997

36. Walker, A. J., Pratt, C. C., \& Eddy, L. (1995). Informal caregiving to aging family members: A critical review. Family Relations. 44, 40211. DOI: $10.2307 / 584996$

37. Wittenberg-Lyles, E., Demiris, G., Oliver, D.P. \& Burt, S. (2011). Reciprocal suffering: Caregiver concerns during hospice care. Journal of Pain and Symptom Management. DOI: 10.1016/j.jpainsymman.2010. 04.026 